\title{
Comparison Study: Taguchi Methodology vis.-a-vis. Response Surface Methodology Through a Case Study of Accelerated Failure in Spin-on-Filter
}

\author{
Raykundaliya, D.P. ${ }^{1}$, Shanubhogue, A. ${ }^{2}$ \\ Assistant Professor, Department of Statistics, Sardar Patel University, Vallbh Vidyangar-Anand, India ${ }^{1}$ \\ Professor, Department of Statistics, Sardar Patel University, Vallbh Vidyangar-Anand, India ${ }^{2}$
}

\begin{abstract}
In this paper we investigate the choice of best combination of factors for $2^{7} \times 3^{1}$ mixed factorial design in 16 runs through Taguchi Design Method and Response Surface Method (RSM). Further we show that Response Surface Method predicts better optimal response ( $9.72 \%$ more) as compared to optimum response obtained through Taguchi Design Method. The comparison of methods is done with the help Spin-on-Filter case study conducted by [1]. We use MINITAB for the analysis under both methods.
\end{abstract}

Keywords: Spin-on-filter (SOF); Taguchi Design Method; Signal-to-noise ratio; Response Surface Method; Dynamic life of SOF; Choice of the best factors combination; ANOVA

\section{INTRODUCTION}

A spin-on-filter (SOF) is an important integral component (iv) of oil-operated generator sets and automobiles. It is used (v) for filtering the lubrication oil and fuel. In particular, its (vi) function is to remove the unwanted dirt and heavy (vii) particles. Thus, this component is useful for preventing the (viii) plugging and restriction of injectors. The SOF, while in use goes through various operating load conditions that contribute to wear and tear. As a result, the SOF will, at some point of time, either break off or start leaking at the seamed locations. The number of cycles at which the leak of break starts is defined as the dynamic life of the SOF i.e. variable of our interest, say $y$. To increase efficiency of the system of which this component is a part it is desirable for higher dynamic life of the SOF. To achieve the desirable result a study was conducted through an newly installed production process. Acceptable dynamic life was set as the survival of filters at least $10^{5}$ cycles. Before undertaking this study, the manufacturing company used conditional process settings in production of the SOFs. It was found that $20 \%$ of SOFs did not survive for at least $10^{5}$ cycles. The study of comparison between Taguchi Design Method and Response Surface Method for hybrid microcircuit assembly processing have found in [3]. Further, they show that Response Surface Method has better efficiency than Taguchi Design Method.

\section{SOF Production Process}

The SOF is an assembly of a filter element, shell, nut plate and retainer. Further filter element itself is an assembly of a filter paper, center tube, end plate and spring. The SOF manufacturing process is mainly classified in following eight steps:
(i) Pleating
(ii) Knuckle setting
(iii) Clipping

Copyright to IARJSET

\author{
End plate attachment \\ Curing \\ Welding \\ Seaming \\ Screen printing and packing
}

The details of process steps is given in Dharmadhikari et al (2000).

\section{THE DESIGN OF EXPERIMENT FOR THE DYNAMIC LIFE OF SOF}

To use statistical approach in designing and analyzing an experiment, it is necessary to follow the basic guideline for conducting the experiment. The basic steps of guideline of design of experiments are:

(i) Recognition and statement of the problem: Here our approach is to investigate choice of best combination of factors as a result optimum value of dynamic life of SOF.

(ii) Choice of factors, levels and ranges: Brainstorming with experienced engineers and feasible operating ranges of machines and materials help to decide the experimental factors.

(iii) Choice of experimental design: The study conducted for eight factors in 16 runs. The seven factors at two levels and eighth factor at three levels. The descriptions of these factors are given in Table 1 following to [1]. In statistical language our objective is to study main effects and interaction effects in this mixed factorial experiment. To conduct such an experiment $\mathrm{L}_{16}$ orthogonal array given by Taguchi or simultaneously one can construct through fractional factorial design [2]. We also note that for all factors at level 1 (level 2: B) denotes the level under ongoing practice and level 2 indicates the potential new value of the setting. To analyze the data 
through Taguchi design method we require minimum two optimum dynamic life of SOF is $1,12,434$ cycles more replications i.e. the dynamic life of two different SOF of than $10^{5}$ cycles.

each factor combination are observed. For details B. Response Surface Method regarding Taguchi design method and fractional factorial experiment readers may refer [2].

(iv) Performing the experiment and collection of data: As the experiments are conducted in laboratory or like Response Surface Methodology (RSM), is a collection of mathematical and statistical techniques that are useful for modelling and analysing of problems in which a response laboratory environment the experimenter should first create the same environment which is the actual environment for the product outside the laboratory. To carryout test on SOF in laboratory environment is created like environment in automobile engine for SOF. To complete the experiment in limited time frame extra mechanical stress supplied from outside in process i.e. accelerated failure can be observed dynamic life time of SOF. A filter put on test continue to operate without failure until the end of the second day, its life has to be greater than $10^{5}$ cycles. Dynamic life cycles of obtained through a counter. Each filter was put on test and removed upon failure or at the end of the second day, which ever occurred first. This experiment is conducted by [1] and its outcome are given in Table 2. The failure (uncensored) observation and survival SOF observation indicated through status column in Table 2 by 0 and 1 respectively.

(v) Statistical Analysis of Data

(vi) Conclusions and recommendation

Step (v) and (vi) are discussed in details in the section of Statistical Analysis for Taguchi Design Method and Response Surface Method.

\section{IV.STATISTICAL ANALYSIS FOR TAGUCHI DESIGN METHOD AND RESPONSE SURFACE METHOD}

\section{A. Taguchi Design Method}

Here we note that the life of a SOF is a "larger-the better" type of characteristic. The signal-to-noise ratios are calculated through the equation for "larger-the-better" type

$\eta_{i}=-\log \left(\frac{1}{-} \sum_{j=1}^{n} \frac{1}{y_{i j}^{2}}\right)$

where $y_{i j}$ is the $j$ th observation from the $i$ th run and $n$ is number of replications of the $i$ th run. In our case we have $n=2$ and values for $\eta_{i}$ can be calculated for dynamic life of SOF. The resultant output obtained by analyzing data in Table 2 using MINITAB software is given in Table 3. Here again it is to be noted that Taguchi design is analysed for main effects for all factor and one interaction $A B$ suggested by engineers.

In Taguchi Design Method the level of factor is considered for optimum response is based on the maximum value of signal-to-noise ratio among the levels of each factor. The resultant recommended level of factors for the production of dynamic life of SOF having optimum life is given in Table 4. The predicted dynamic life for the recommended choice of factor combinations can be obtained through inverting the optimum noise-tosignal ratio as a function of $y$. The optimum value of noise-to-signal ratio for the factor combination recommended in Table 4 is 102.00 and corresponding

of interest is influenced by several variables (factors) and objective is to optimize this response[2].

In RSM problems, the form of the relation is unknown. Thus the first step is to find approximate functional relationship between $y$ and set of independent variables $\underline{x}$. The statistical form of RSM:

$$
y=f(\underline{x})+\varepsilon
$$

where $\varepsilon$ represents the noise or error observed in the response $y$. Our objective is to investigate the best choice factor combination which gives optimum value of response on the surface of responses. The first step of RSM is to investigate the distribution of average dynamic life of SOF (avelife). The distribution of average dynamic life of SOF is found to be Normal from its Normal Probability Plot (Figure 2). One can refer for detail [3-4]. Further the p-value of Anderson-Darling test of fitting of normal distribution for avelife is 0.644 (>0.05) which indicates, the normal distribution fits well to avelife of SOF.

Before fitting RSM to the data given in Table 2 to identify which effect terms to be included in the model we draw main effect plots and interaction effect plots for all factors given in Figure 3((a)-(b)).

The analysis of average dynamic life of SOF is carried out through option of Response Surface in MINITAB by providing all main effects and possible interactions effects from interaction plots. This analysis is done for un-coded observations in MINITAB. The resultant output is given in Table 5 (Estimates of effects) and Table 6 (Analysis of Variance Table)

The value of goodness of fit R-Square for fitted model is $85.6 \%$ which indicates that $85.6 \%$ of total variation of dynamic life of SOF is explained by the fitted model. Further from Table 6 of Analysis of Variance of SOF, the p-value for linear and interaction term are greater than 0.05 suggest that first order Response Surface model is sufficient to obtain optimum value of dynamic life of SOF. In Table 5 of estimated regression coefficients, it is observed that all main effects are insignificant at 5\% level of significance and interaction effect $A G$ is only significant at $5 \%$ level of significance because p-value correspond to interaction effect AG is 0.045 ( $<0.05$ ). Therefore, the fitted Response Surface model for average dynamic life of SOF is

$$
\begin{aligned}
& y=187420-4526 x_{1}+8120 x_{2}-37483 x_{3} \\
& +10825 x_{4}-1474 x_{5}-2887 x_{6}-56492 x_{7} \\
& -45131 x_{8}-520 x_{1} x_{2}+40598 x_{1} x_{7}+21695 x_{1} x_{8}
\end{aligned}
$$

From study of main effect plots of average dynamic life SOF for all factors (Figure 3(a)), the recommended best combination of level of factors is given in Table 7 .

The optimum value of $y$ for above recommended levels of factor for the production of SOF using equation (3) is 1, 
23,926 cycles. Further, it is to be noted that RSM would give $9.72 \%$ more optimal value compared to Taguchi method.

\section{CONCLUSION AND RECOMMENDATION}

In Section 4 we obtain the optimum value of average dynamic life of SOF through Taguchi method and Response Surface Methodology is 112,434 and 123,926 respectively. From these two numbers of life cycle we can say RSM gives $9.72 \%$ more optimal value compared to Taguchi method.

\section{A. ADVANTAGES OF USING RESPONSE SURFACE} METHODOLOGY

1. It is a Statistical/Mathematical modelling technique.

2. It can help to find optimum value for response beyond or within the range of level of factors suggested by engineers.

3. It will help to identify the future direction of optimum response, at where optimum can possible.

4. It can also identify the interaction or curvature effects beyond the imagination of engineers.

5. It can also investigate statistical significance of effects. As a result on can construct $95 \%$ confidence interval for the values such effects which can help to identify future range of level of factors.

\section{B. DisadVANTAGES OF TAGUCHI DESIGN METHOD}

1. It is purely a philosophical, no Mathematics involved.

2. It gives only the optimum value at any levels specified by experimenter

3. It will not give the future direction of optimum response in experiments. Further, the future direction of optimum require to conduct one more new experiment

\section{ACKNOWLEDGMENT}

This research is funded by University Grant Commission (UGC) for Minor Research Project (F.37-549/2009(SR)). The First author wishes to thank Prof. D.K.Ghosh for helpful discussion during his visit in Department and Dr.Jyoti M.Divecha for helpful discussion

\section{REFERENCES}

[1] Dharmadhikar, D.A., Kharshikar, V.A., Ratnaparkhi, M.V and Prasad, K. (2000). "Analyzing the Censored Life Data arising in Fractional Factorial Designs: Spin-on-filter Case Study”. Quality Engineering, 13(1), 65-72

[2] Montgomery, D.C. (2004). Design and Analysis of Experiments, Edition V John Wiley and Sons (Asia)

[3] Raykundaliya, D.P. and Shanubhogue, A.(2011) "A Case Study of Hybrid Microcircuit Assembly Process using Taguchi Design Method and Response Surface Method". PRAJNA: Journal of Pure and Applied Sciences Vol. 19 pp 90-92

[4] Shanubhogue, A and Raykundliya, D.P. (2009). "A Statistical Study of ATM of a Nationalized Bank Branch”, Prajna-Journal of Pure and Applied Sciences. Vol. 17 199-202.

[5] http://en.wikipedia.org/wiki/Oil_filter
Figure 1: Image of Spin-on-Filter (SOF) used in Automobile [5]

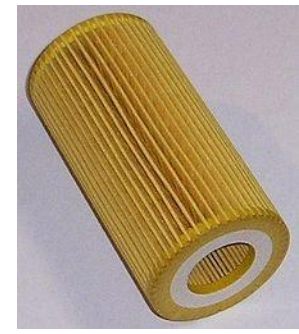

Figure 2: Normal Probability Plot of Average Life Cycle of SOF

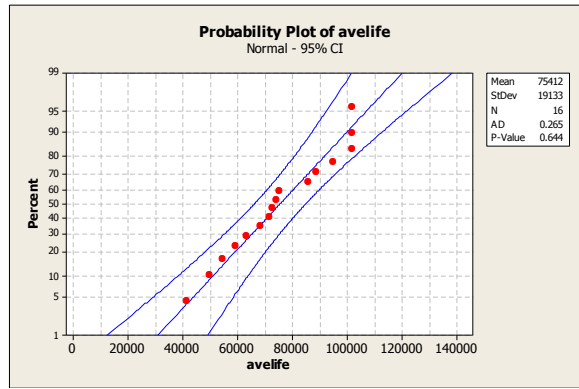

Figure 3: Main Effect Plots and Interaction Effect Plots for avelife

(a)

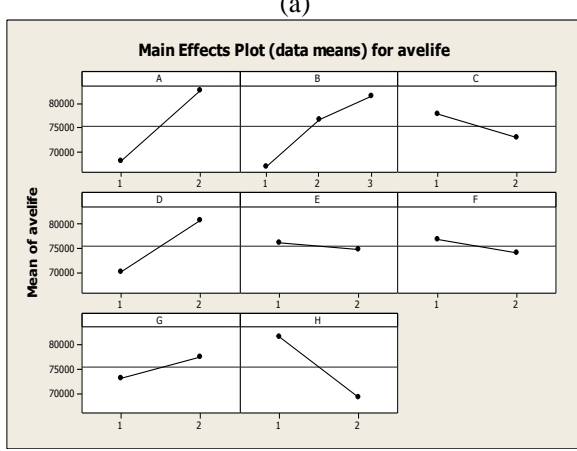

(b)

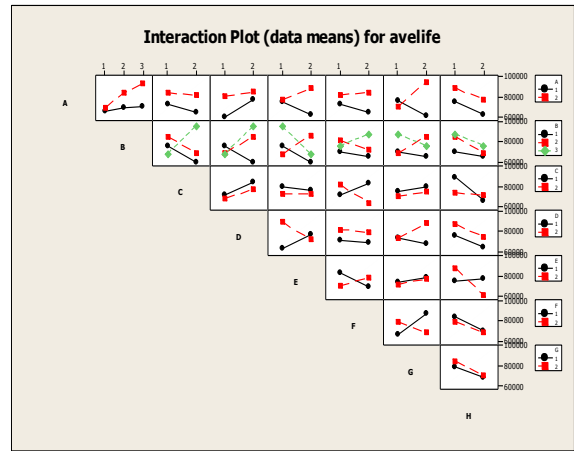


International Advanced Research Journal in Science, Engineering and Technology

Vol. 2, Issue 3, March 2015

Table 1: Factors and their Levels

\begin{tabular}{|c|c|c|c|c|c|c|c|}
\hline \multirow{2}{*}{ Description } & \multirow{2}{*}{ Process } & \multirow{2}{*}{$\begin{array}{c}\text { Factor } \\
\text { (variable) }\end{array}$} & \multirow{2}{*}{$\begin{array}{c}\text { Present } \\
\text { level }\end{array}$} & \multicolumn{3}{|c|}{ Experimental levels } & \multirow{2}{*}{ Unit } \\
\hline & & & & 1 & 2 & 3 & \\
\hline Air Pressure & Welding & $\mathrm{A}\left(x_{1}\right)$ & 25 & 25 & 32 & - & psi \\
\hline Stroke Pressure & Welding & $\mathrm{B}\left(x_{2}\right)$ & 101 & 100 & 101 & 102 & $\mathrm{~mm}$ \\
\hline Nut plate retainer concentricity & Welding & $\mathrm{F}\left(x_{6}\right)$ & $<0.03$ & $<0.03$ & $0.03-0.06$ & - & in. \\
\hline Roller-1 horizontal gap & Seaming & $\mathrm{C}\left(x_{3}\right)$ & 0.114 & 0.114 & 0.112 & - & in. \\
\hline Roller-2 horizontal gap & Seaming & $\mathrm{D}\left(x_{4}\right)$ & 0.095 & 0.095 & 0.093 & - & in. \\
\hline Roller-1 vertical gap & Seaming & $\mathrm{H}\left(x_{8}\right)$ & 0.05 & 0.05 & 0.15 & - & in. \\
\hline Roller-2 vertical gap & Seaming & $\mathrm{E}\left(x_{5}\right)$ & 0.05 & 0.05 & 0.15 & - & in. \\
\hline Lip width & & $\mathrm{G}\left(x_{7}\right)$ & 3.45 & 3.45 & 3.95 & - & $\mathrm{mm}$ \\
\hline
\end{tabular}

Table 2: Experimental Design and Outcome of Experiments

\begin{tabular}{|c|c|c|c|c|c|c|c|c|c|c|c|c|}
\hline $\begin{array}{l}\text { Run } \\
\text { No. }\end{array}$ & A & B & $\mathrm{C}$ & D & $\mathrm{E}$ & $\mathrm{F}$ & $\mathrm{G}$ & $\mathrm{H}$ & Status ${ }^{\#}$ & life & Status $^{\#}$ & Life \\
\hline 1 & 1 & 1 & 1 & 1 & 1 & 1 & 1 & 1 & 0 & 101,962 & 1 & 48,635 \\
\hline 2 & 1 & 1 & 2 & 2 & 2 & 2 & 2 & 2 & 1 & 50,110 & 1 & 58,947 \\
\hline 3 & 2 & 1 & 1 & 1 & 1 & 2 & 2 & 2 & 1 & 72,737 & 1 & 76,003 \\
\hline 4 & 2 & 1 & 2 & 2 & 2 & 1 & 1 & 1 & 0 & 101,962 & 1 & 24,770 \\
\hline 5 & 1 & 2 & 1 & 2 & 2 & 1 & 1 & 2 & 1 & 71,235 & 1 & 65,320 \\
\hline 6 & 1 & 2 & 2 & 1 & 1 & 2 & 2 & 1 & 1 & 65,664 & 1 & 17,550 \\
\hline 7 & 2 & 2 & 1 & 2 & 2 & 2 & 2 & 1 & 0 & 101,962 & 0 & 101,962 \\
\hline 8 & 2 & 2 & 2 & 1 & 1 & 1 & 1 & 2 & 1 & 48,136 & 1 & 70,770 \\
\hline 9 & 1 & 3 & 1 & 1 & 2 & 1 & 2 & 2 & 1 & 50,539 & 1 & 48,850 \\
\hline 10 & 1 & 3 & 2 & 2 & 1 & 2 & 1 & 1 & 1 & 75,710 & 0 & 101,962 \\
\hline 11 & 2 & 3 & 1 & 1 & 2 & 2 & 1 & 1 & 1 & 69,615 & 0 & 101,962 \\
\hline 12 & 2 & 3 & 2 & 2 & 1 & 1 & 2 & 2 & 0 & 101,962 & 0 & 101,962 \\
\hline 13 & 1 & 2 & 1 & 2 & 1 & 1 & 2 & 1 & 1 & 87,701 & 0 & 101,962 \\
\hline 14 & 1 & 2 & 2 & 1 & 2 & 2 & 1 & 2 & 1 & 41,692 & 0 & 101,962 \\
\hline 15 & 2 & 2 & 1 & 2 & 1 & 2 & 1 & 2 & 1 & 43,708 & 0 & 101,962 \\
\hline 16 & 2 & 2 & 2 & 1 & 2 & 1 & 2 & 1 & 0 & 101,962 & 0 & 101,962 \\
\hline
\end{tabular}

${ }^{\#} 1$ : uncensored observation; 0 : censored observation

Table 3: Response Value Table for Signal-to-Noise Ratio

\begin{tabular}{|c|c|c|c|c|c|c|c|c|}
\hline \multirow{2}{*}{ Level } & \multicolumn{9}{|c|}{ Factor } \\
\cline { 2 - 9 } & $\mathbf{A}$ & $\mathbf{B}$ & $\mathbf{C}$ & $\mathbf{D}$ & $\mathbf{E}$ & $\mathbf{F}$ & $\mathbf{G}$ & H \\
\hline $\mathbf{1}$ & 95.20 & 94.64 & 97.10 & 95.36 & 96.16 & 96.49 & 95.61 & 96.35 \\
\hline $\mathbf{2}$ & 97.11 & 96.11 & 95.21 & 96.74 & 96.14 & 95.82 & 96.69 & 95.96 \\
\hline $\mathbf{3}$ & - & 97.74 & - & - & - & - & - & - \\
\hline
\end{tabular}

Table 4: Recommended Levels of Factors for the Production of SOF

\begin{tabular}{|c|c|c|c|c|c|c|c|c|}
\hline & \multicolumn{9}{|c|}{ Factor } \\
\cline { 2 - 9 } & $\mathbf{A}$ & $\mathbf{B}$ & $\mathbf{C}$ & $\mathbf{D}$ & $\mathbf{E}$ & $\mathbf{F}$ & $\mathbf{G}$ & H \\
\hline Level & 2 & 3 & 1 & 2 & 1 & 1 & 2 & 1 \\
\hline
\end{tabular}

Table 5: Estimated Regression Coefficients for Average Dynamic Life of SOF

\begin{tabular}{|c|c|c|c|c|}
\hline Term & Coefficient & SE coefficient & T & P-value \\
\hline Constant & 187420 & 54806 & 3.420 & $0.027^{*}$ \\
\hline A & -45256 & 35854 & -1.262 & 0.275 \\
\hline B & 8120 & 21673 & 0.375 & 0.727 \\
\hline
\end{tabular}


International Advanced Research Journal in Science, Engineering and Technology Vol. 2, Issue 3, March 2015

\begin{tabular}{|c|c|c|c|c|}
\hline C & -37483 & 30650 & -1.223 & 0.288 \\
\hline D & 10825 & 7032 & 1.539 & 0.199 \\
\hline E & -1474 & 7032 & -0.210 & 0.844 \\
\hline F & -2887 & 7032 & -0.411 & 0.762 \\
\hline G & -56492 & 22236 & -2.541 & 0.064 \\
\hline H & -45131 & 30650 & -1.472 & 0.215 \\
\hline AB & -520 & 14063 & 2.887 & 0.972 \\
\hline AG & 40598 & 14063 & 1.091 & $0.045^{*}$ \\
\hline CH & 21695 & 19888 & & 0.337 \\
\hline
\end{tabular}

$\mathrm{S}=\mathbf{1 4 0 6 3} \quad \mathrm{R}-\mathrm{sq}=\mathbf{8 5 . 6 \%} \quad *$ p-value $(<0.05)$

Table 6: Analysis of Variance of Average Dynamic Life of SOF

\begin{tabular}{|c|c|c|c|c|c|}
\hline \multicolumn{1}{|c|}{ Source } & DF & Adj. SS & Adj. MS & F & P-value \\
\hline Regression & 11 & 470020009 & 427290917 & 2.16 & 0.238 \\
\hline Linear & 8 & 2453608926 & 306701116 & 1.55 & 0.354 \\
\hline Interaction & 3 & 209682907 & 698943069 & 3.53 & 0.127 \\
\hline Residual Error & 4 & 791084178 & 197771044 & & \\
\hline Total & 15 & & & & \\
\hline
\end{tabular}

